\title{
ArcheoSciences
}

Revue d'archéométrie

33 (suppl.) | 2009

Mémoire du sol, espace des hommes

\section{The square array revisited: a lightweight multisensor platform for vulnerable soil environments}

Andrew Parkyn, Chris Gaffney, Armin Schmidt and Roger Walker

\section{(2) OpenEdition Journals}

Electronic version

URL: https://journals.openedition.org/archeosciences/1795

DOI: 10.4000/archeosciences. 1795

ISBN: 978-2-7535-1599-4

ISSN: $2104-3728$

Publisher

Presses universitaires de Rennes

\section{Printed version}

Date of publication: 30 October 2009

Number of pages: $333-334$

ISBN: 978-2-7535-0943-6

ISSN: $1960-1360$

\section{Electronic reference}

Andrew Parkyn, Chris Gaffney, Armin Schmidt and Roger Walker, "The square array revisited: a lightweight multisensor platform for vulnerable soil environments", ArcheoSciences [Online], 33 (suppl.) | 2009, Online since 30 October 2011, connection on 21 September 2021. URL: http:// journals.openedition.org/archeosciences/1795; DOI: https://doi.org/10.4000/archeosciences. 1795 


\title{
The square array revisited: a lightweight multisensor platform for vulnerable soil environments
}

\author{
Andrew Parkyn*, Chris Gaffney**, Armin Schmidt ${ }^{* * *}$ and Roger Walker
}

Key words: Square array, MSP40, Cart, Vulnerable soils, Light weight.

The square array was initially tested in the UK during the 1960s by Anthony Clark. However, since the development of the twin probe system, the square array has been seldom used in the UK, although greater use has been reported elsewhere, especially in France (Panissod et al., 1998). In the last few years, re-investigation of the square array's potential in an archaeological context has reignited interest and led to the development of a hand-pulled cart system by Dr. Roger Walker (Geoscan Research). This cart system incorporates earth resistance and gradiometer instruments to allow simultaneous surveys with a lightweight device.

The main objective of the project is to test the application of the MSP 40 on a variety of sites and to encourage the use of appropriate geophysical survey equipment to minimize the impact and therefore protect even the most vulnerable of archaeological sites.

Primarily this is linked to surveys over thin or otherwise vulnerable soils that have a high archaeological potential. Such sites may be prone to erosion or damage from agricultural practices (ploughing) where heavy geophysics equipment or repeated trampling during surveys may cause further damage.

A number of sites in the Yorkshire Wolds have been identified for study due to their vulnerability brought about by modern agricultural practices (ploughing) on thin soil. The data collected are compared with previous geophysical work on the sites and will help monitor soil erosion. As the cart is conventionally set up as a square array, it also has the advantage of collecting both alpha and beta data sets (longitudinal and broadside traverses) simultaneously. The data sets can then be combined to create a new data set free from anisotropy. The cart also has the potential for a number of other complementary sensors to be added to the cart without significantly enhancing the weight of the cart enabling more information to be gained during a single survey.

The MSP40 has a number of advantages compared to other cart systems; the cart is hand drawn and so can be more easily manoeuvered into position than mechanically pulled systems which often require large turning circles (see Fig. 1). It can also be easily transported in the back of a car. The speed of survey is significantly increased when compared to manual earth resistance frames and the use of the square array has the additional advantage of not having trailing wires like standard twin probe surveys. The rapid data collection available, about seven and a half minutes per $20 \mathrm{~m}^{2}$ grid at a $1 \mathrm{~m}$ line separation, makes the cart a valuable tool for both research and commercial companies as a means of collecting earth resistance data and fluxgate gradiometer data at the same time. As this can be accomplished with a single operator there is potential for saving time and money.

* PhD. student Division of Archaeological, Geographical and Environmental Sciences, University of Bradford, Bradford, West Yorkshire, BD7 1DP, UK. (a.k.parkyn@bradford.ac.uk)

** Division of Archaeological, Geographical and Environmental Sciences, University of Bradford, Bradford, West Yorkshire, BD7 1DP, UK.

*** Geoscan Research, Heather Brae, Chrisharben Park, Clayton, Bradford, West Yorkshire BD14 6AE, UK. 


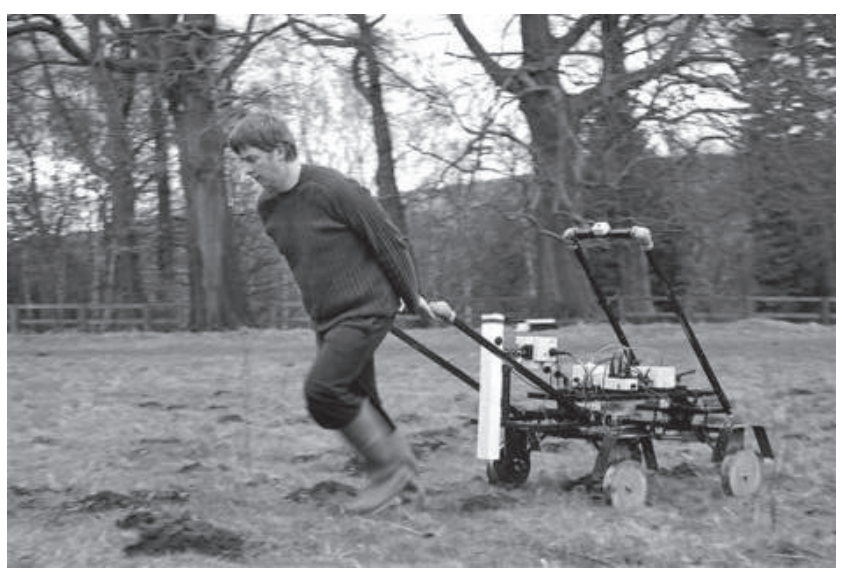

Figure 1: Showing the MSP40 being pulled by hand during a survey.

The instrumentation also allows for a higher resolution survey up to a sampling interval of $0.125 \mathrm{~m}$ or 8 readings per meter due to the continuous contact with the ground and the fast sampling rates of modern earth resistance meters.

By using either a time based or a wheel-encoder system, the cart offers great flexibility as it can be used to survey larger $(\geq 20 \mathrm{~m})$ grid squares with greater accuracy by using a distance rather than time based recording method. An in-built spike monitor reduces potential errors by making the surveyor aware of issues in the field.

As the spike length on the wheels can be adjusted, part of the research is to assess each wheel configuration of the cart's potential impact on the soil. The optimal wheel configuration is tested by using the cart with various spike lengths on different types of ground cover, recording the amount of soil disturbance from the wheels and any potential noise in the data due to poor contact resistance. Such information will further enable the consideration of the possible applications outside of archaeological geophysics as a means of assessing sensitive or problematic sites. Using wheels without spikes may potentially be a way of enabling archaeological investigations on sites known to contain unexploded mortar shells as well as forming the basis of a UXO framework for site investigation. Additional uses of non-spiked wheels may also include allowing geophysical work on sites with young plants in order to assess the archaeological potential on agricultural land later in the growing season.

The project also includes a seasonality test in order to examine how the results from a square array cart may change over time when compared to twin probe data and a manual square array (see Fig. 2).

The cart design is very adaptable, which means that the instrument is potentially suitable for a variety of sites with a mixture of ground covers. The adaptability and compact
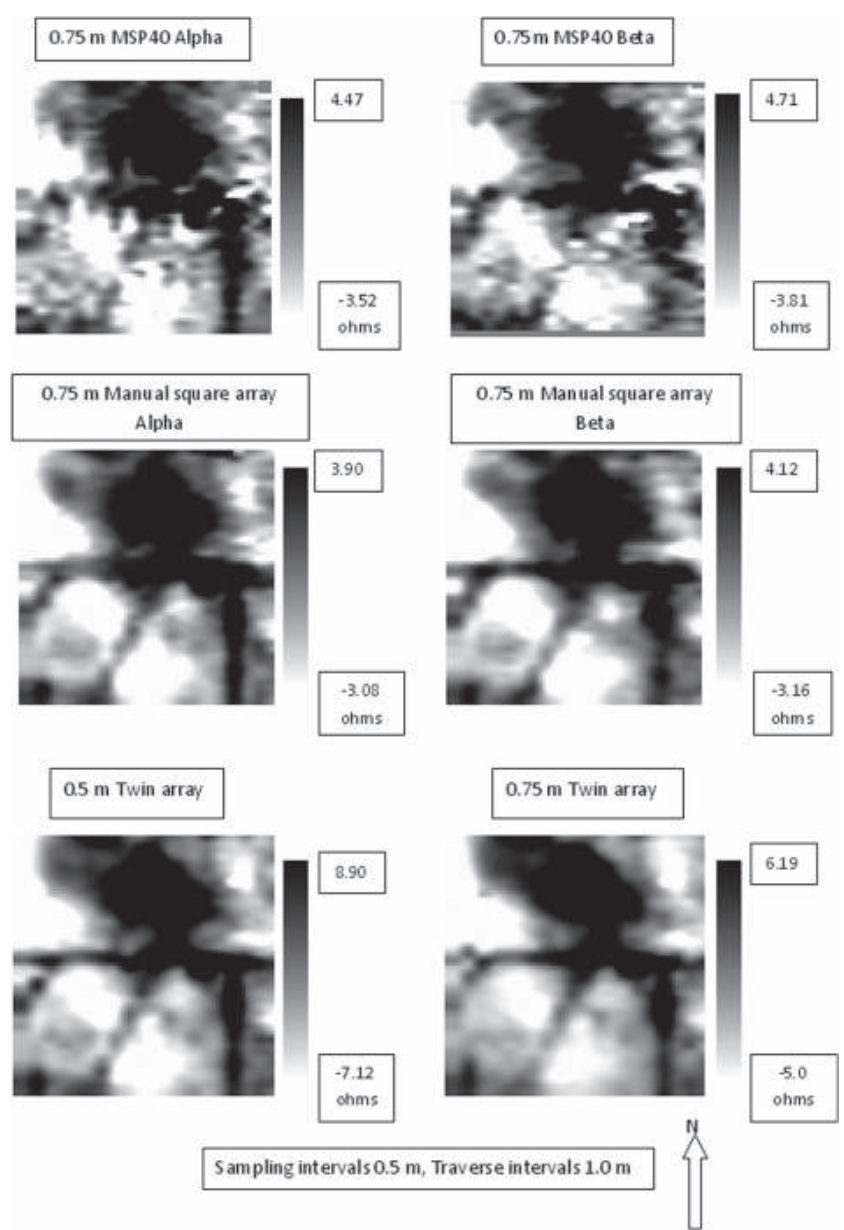

Figure 2: Seasonality Test 18.02.09/array comparisons.

nature of the cart are just two of the many advantages of the cart over other existing towed systems.

The reduced data collection time with multiple methods of data being collected in one traverse, may significantly alter the role of earth resistance data collection in monitoring and exploratory archaeological geophysics. However it is vital to understand what impact the cart may have on a vulnerable site to make an informed decision as to selecting the most appropriate instrumentation.

This is a PhD project funded by the AHRC as part of a collaborative doctoral award, co-sponsored by Geoscan Research.

\section{References}

Panissod, C., Dabas, M., Florsch, N., Hesse, A., Jolivet, A., Tabbagh, A. and Tabbagh, J., 1998. Archaeological Prospecting using Electric and Electrostatic Mobile Arrays. Archaeological Prospection, 5: 239-251. 